\title{
Natal Tooth: A Histomorphologic Variant, a Rarity
}

\author{
Jayachandran Sadaksharam¹ Jesupatham Sophia Jeba Priya
}

${ }^{1}$ Department of Oral Medicine and Radiology, Tamil Nadu Government Dental College and Hospital, Chennai, Tamil Nadu, India

\begin{abstract}
Address for correspondence Jayachandran Sadaksharam, MDS, PhD, MBA, MAMS, FDS, RCPS (Glasgow), Department of Oral Medicine and Radiology, Tamil Nadu Govt. Dental College \& Hospital (Affiliated to Tamil Nadu Dr. M G R Medical University), Chennai 600003, Tamil Nadu, India (e-mail: drsjayachandranmds@yahoo.com).
\end{abstract}

\begin{abstract}
Keywords

- natal teeth

- mandibular incisors

- keratin

- hard tissue

Presence of natal or neonatal teeth in a newborn is rare, that is, 1 in 3,000 cases. Various etiological factors have been put forth explaining the presence of natal teeth but they are not very clear. Although some authors have suggested that these teeth may represent predeciduous supernumerary teeth, most of these teeth represent prematurely erupted portions of the deciduous dentition, not supernumerary teeth. They can be left untreated in some cases if they do not cause any difficulty to the mother while feeding or do not pose a risk of swallowing in the newborn. One such case of natal tooth with histological variation is presented here.
\end{abstract}

\section{Introduction}

Natal teeth are defined as the teeth present at birth. ${ }^{1}$ Natal teeth are also called as congenital teeth. ${ }^{2}$ Neonatal teeth are erupted within 30 days of birth. The etiology of natal and neonatal teeth is unknown, but it is usually attributed to factors such as the hereditary transmission of a dominant autosomal gene, a superficial position of the tooth bud, endocrine disorders, osteoblastic activity in the bud, infection, hypovitaminosis, poor nutrition, and syndromes such as Hallermann-Streiff and Wiedemann-Rautenstrauch syndromes. $^{3-7}$ Superficial positioning of tooth germ increases the rate of eruption of natal and neonatal teeth due to poor nutrition of mother and fetus causing hypovitaminosis, hormonal stimulation, syphilis, and febrile incidence. Incidence of natal teeth is 1:3000 live births. ${ }^{8}$ Most common natal teeth are lower primary central incisors. ${ }^{9}$ Incidence of natal and neonatal teeth is $85 \%$ in mandibular incisors, $11 \%$ in maxillary incisors, $3 \%$ in mandibular canine and molars, and only $1 \%$ in maxillary posterior region. The natal teeth might occur as a familial trait as 8 to $62 \%$ of cases with positive family history have been reported. ${ }^{10}$ Predilection for females was cited by some authors with Kates et al, a 66\% proportion for female against a $31 \%$ proportion for male. ${ }^{11}$ The presence of natal teeth can cause feeding problems, loosening and risk of aspiration, ulceration of ventral part of the tongue and frenulum. ${ }^{9}$

\section{Case Report}

A 24-day-old male preterm baby born to a primi mother who had underwent in vitro fertilization treatment was referred from Military Hospital with a complaint of presence of tooth in the mouth. Patient's mother complained of difficulty in feeding the baby. No other relevant medical history was recorded. Marriage of parents was nonconsanguineous. On examination, a yellowish tooth-like structure ( - Fig. 1) was present in the lower anterior teeth region that was mobile and falls under category 1 of Hebling's classification $(1997)^{1,10}$, that is, shell-like crown loosely attached to the alveolus by a rim of oral mucosa, no roots. Plaque deposits were seen around the tooth with inflamed gingiva (-Fig. 1). The baby was referred to the department of pedodontics. After getting consent from the parents, the natal tooth was extracted under topical lignocaine using Spencer Wells forceps under aseptic conditions ( $\mathbf{- F i g}$. 1B). Hemostasis was achieved by asking the mother to feed the baby immediately after extraction. A sterile cotton was placed and the patient was kept under observation. Follow-up was done. Examination of the extracted tooth revealed a crown with no root that roughly measured $6 \mathrm{~mm}(\boldsymbol{- F i g}$. 2). The tooth was decalcified and subjected to histopathological study. Histopathological section of the tissue showed cellular connective tissue with inflammatory cells with adjacent mineralized tissue resembling bone (- Fig. 3A, B).
DOI https://doi.org/ $10.1055 / \mathrm{s}-0039-3401468$ ISSN 0379-038X.
License terms

() (1) $\odot \circledast$ 

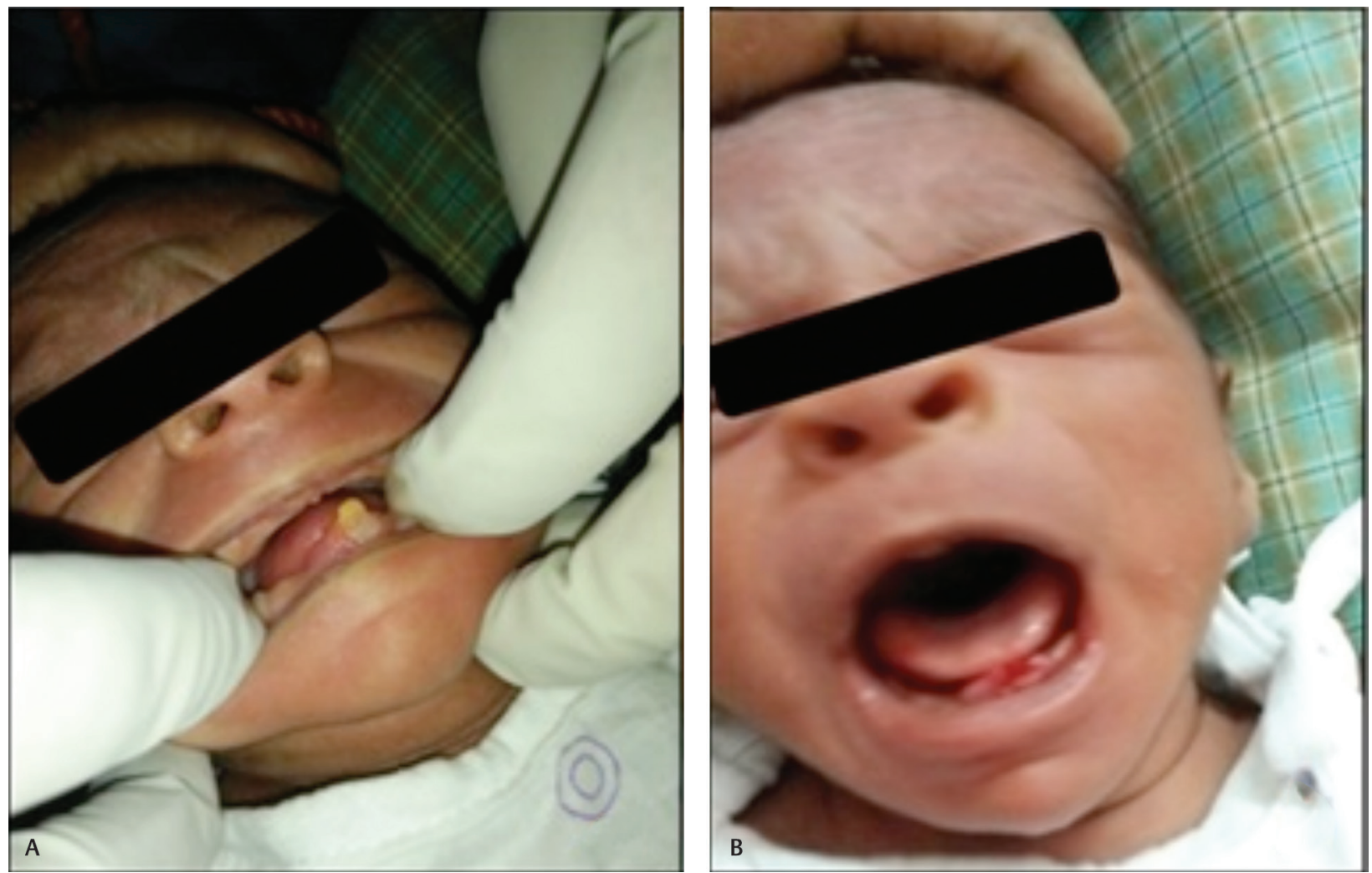

Fig. 1 (A) Yellowish crown appearance of the natal tooth (B) post-extraction.

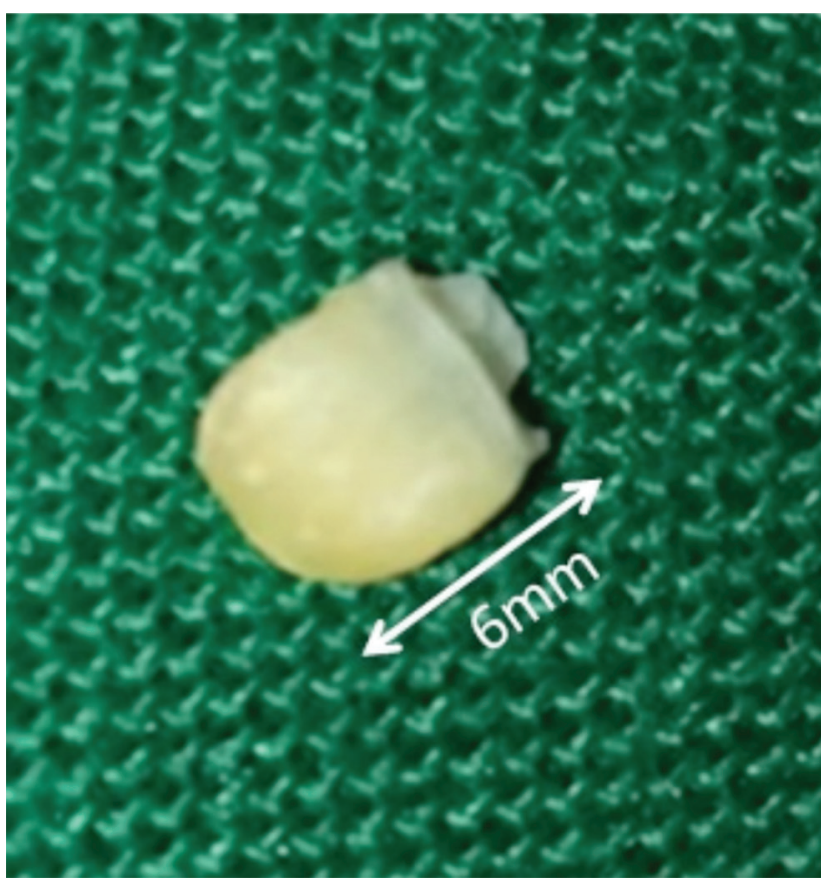

Fig. 2 Extracted tooth.

\section{Discussion}

Natal teeth are also called as dentition praecox, fetal teeth, or early infancy teeth. ${ }^{2}$ Syndromes associated with natal teeth are cleft palate, chondroectodermal dysplasia, HallermannStreiff syndrome, Ellis-Van Creveld syndrome, and Riga-Fede disease. But this case was not associated with any syndrome.
Notwithstanding the normal basic structure of natal teeth, early eruption is associated with abnormal mineralization of the enamel. ${ }^{12,13}$ Histologically, the majority of natal teeth have dysplastic or hypomineralized enamel, irregular dentin and osteodentin in the cervical portions, and interglobular dentin in the coronal regions ${ }^{12,13}$. The incisal edge might lack enamel. Both Hertwig's sheath and cementum might be absent. ${ }^{14,15}$ Sometimes, histologically it resembles only thickened keratin. But in this case, the histological appearance was completely different and the hard tissue resembled bone. Knowing how to manage natal teeth is important for proper well-being of a child. In this case, even though the natal tooth caused mild problem in feeding, it was mobile. So, it was extracted to avoid aspiration of the tooth. Natal teeth must be approached individually with sound clinical judgment guiding appropriate therapy.

\section{Conclusion}

Managing a child born with natal tooth can be challenging as it poses problems in feeding, increased risk of aspiration, and causes ulceration of the tongue. Presence of supernumerary teeth should be suspected if there is a significant delay in the eruption of a localized portion of the dentition. Early diagnosis and treatment often are crucial in minimizing the aesthetic and functional problems of the adjacent teeth. Parental counseling, guidance, and proper decision making are important. Obstetricians and gynecologists and pediatricians should refer neonates born with teeth to the dental surgeons for expert management. 

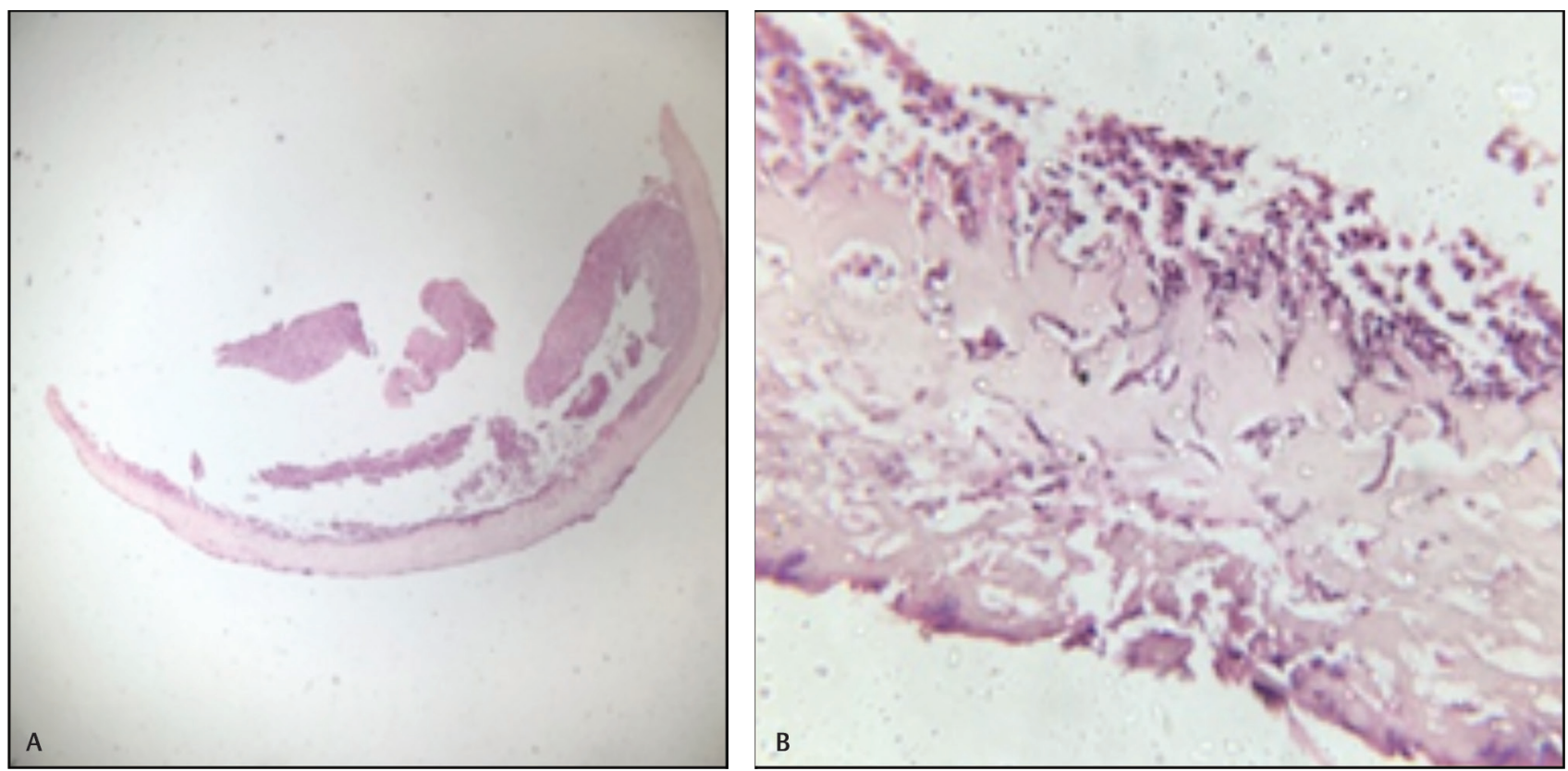

Fig. 3 (A) HPE section of the decalcified tooth under $x 4$ magnification. (B) HPE section of the decalcified tooth under $x 10$ magnification showing connective tissue and bone like tissue. HPE, histopathological examination.

\section{Conflict of Interest}

None declared.

\section{References}

1 Cunha RF, Boer FAC, Torriani DD, Frossard WT. Natal and neonatal teeth: review of the literature. Pediatr Dent 2001;23(2):158-162

2 Massler M, Savara BS. Natal and neonatal teeth; a review of 24 cases reported in the literature. J Pediatr 1950;36(3):349-359

3 Ooshima T, Mihara J, Saito T, Sobue S. Eruption of tooth-like structure following the exfoliation of natal tooth: report of case. ASDC J Dent Child 1986;53(4):275-278

4 Bigeard L, Hemmerle J, Sommermater JI. Clinical and ultrastructural study of the natal tooth: enamel and dentin assessments. ASDC J Dent Child 1996;63(1):23-31

5 Tunc T, Bulbul A, Erdinc K, Sarici SU, Gul D, Ozcan O. The Wiedemann-Rautenstrauch or neonatal progeroid syndrome: report of a patient with hypospadias. Genet Couns 2009;20(4):367-371

6 Robotta P, Schafer E. Hallermann-Streiff syndrome: case report and literature review. Quintessence Int 2011;42(4):331-338
7 Venkatesh C, Adhisivam B, Mhaske A, et al. Natal teeth in an infant with congenital hypothyroidism. Indian J Dent Res 2011;22(3):498

8 Chowdhary S, Tandon S. Congenital teeth: superstition and reality - a case report and review of literature. Int J Sci Stud 2014;1(5):53-56

9 Kates GA, Needleman HL, Holmes LB. Natal and neonatal teeth: a clinical study. J Am Dent Assoc 1984;109(3):441-443

10 Leung AK, Robson WL. Natal teeth: a review. J Natl Med Assoc 2006;98(2):226-228

11 Seminario AL, Ivancaková R. Natal and neonatal teeth. Acta Med (Hradec Kralove) 2004;47(4):229-233

12 Uzamis M, Olmez S, Ozturk H, Celik H. Clinical and ultrastructural study of natal and neonatal teeth. J Clin Pediatr Dent 1999;23(3):173-177

13 Galassi MS, Santos-Pinto L, Ramalho LTO. Natal maxillary primary molars: case report.J Clin Pediatr Dent 2004;29(1):41-44

14 McDonald RE, Avery DR. Dentistry for the Child and Adolescent. 3rd edition. Saint Louis: Mosby; 1978

15 Neville BW, Damm DD, Allen CM, Chi AC. Oral and Maxillofacial Pathology. 4th ed. Saunders, Philadelphia: Elsevier; 2015 